\title{
Oral Therapies for Multiple Sclerosis
}

\author{
Simon Faissner and Ralf Gold \\ Department of Neurology, St. Josef-Hospital, Ruhr-University Bochum, 44791 Bochum, Germany \\ Correspondence: ralf.gold@rub.de
}

Multiple sclerosis treatment faces tremendous changes owing to the approval of new medications, some of which are available as oral formulations. Until now, the four orally available medications, fingolimod, dimethylfumarate (BG-12), teriflunomide, and cladribine have received market authorization, whereas laquinimod is still under development. Fingolimod is a sphingosine-1-phosphate inhibitor, which is typically used as escalation therapy and leads to up to $60 \%$ reduction of the annualized relapse rate, but might also have neuroprotective properties. In addition, there are three more specific S1P agonists in late stages of development: siponimod, ponesimod, and ozanimod. Dimethylfumarate has immunomodulatory and cytoprotective functions and is used as baseline therapy. Teriflunomide, the active metabolite of the rheumatoid arthritis medication leflunomide, targets the dihydroorotate dehydrogenase, thus inhibiting the proliferation of lymphocytes by depletion of pyrimidines. Here we will review the mechanisms of action, clinical trial data, as well as data about safety and tolerability of the compounds.

$D^{\prime \prime}$ uring the last decade, the treatment of multiple sclerosis (MS) made tremendous advances with the development of new therapeutics, which show greater efficacy than the "old" first-line therapies, interferons (IFNs), and glatiramer acetate. By now, clinicians have an armamentarium of more than ten compounds at their disposal. In 2009 and/or 2010, fingolimod received market authorization by the U.S. Food and Drug Administration (FDA) as the first orally available medication for relapsing remitting MS (RRMS). This was welcomed, especially by patients who preferred the oral way of administration. Since approval of fingolimod, a number of new medications have been developed and approved such as dimethylfumarate (DMF) and teriflunomide or are under development such as laquinimod and more specific S1P-agonists. Here we will review the mechanisms of action of orally available MS therapeutics, the pivotal clinical trial data, as well as safety and tolerability of the compounds.

\section{CLADRIBINE}

Cladribine is a purine nucleoside that is phosphorylated in cells with a high amount of deoxycytidine kinase to the active form, 2-chlorodeoxyadenosine-ATP, which accumulates in the nucleus (Beutler 1992). This leads to a disturbance of the cellular metabolism and DNA damage, hence, inducing cell death. This process occurs mostly in lymphocytes as they contain high amounts of deoxycytidine kinase, thereby mediating beneficial effects in RRMS. In 2011, cladribine was refused market authorization in Europe and the United States because of an unfavorable efficacy/side effect profile mainly

Editors: Howard L. Weiner and Vijay K. Kuchroo

Additional Perspectives on Multiple Sclerosis available at www.perspectivesinmedicine.org

Copyright (C) 2019 Cold Spring Harbor Laboratory Press; all rights reserved; doi: 10.1101/cshperspect.a032011

Cite this article as Cold Spring Harb Perspect Med 2019;9:a032011 
based on a high rate of secondary malignancies. In 2016, Merck applied again for market authorization in the European Union, because followup data and the ORACLE study in clinically isolated syndrome (CIS) patients did not confirm the malignancy risk. Cladribine was approved in summer 2017 for highly active relapsing MS.

\section{Mechanisms}

Cladribine crosses the blood-brain barrier and also exerts effects on central nervous system (CNS) cells. Microglia treated with cladribine show reduced proliferation and apoptosis (Singh et al. 2012). In experimental autoimmune encephalomyelitis (EAE), an animal model of MS, cladribine did not show an effect on microglial or astroglial activation, but reduced glutamatergic synaptopathy which is associated with central inflammation (Musella et al. 2013). Cladribine also affects the T-cell priming capacity of dendritic cells, hence, resulting in reduced induction of IFN- $\gamma$ and tumor necrosis factor $\alpha$ (TNF- $\alpha$ ) (Kraus et al. 2014). The molecule also leads to a decrease of circulating $B$ cells and $\mathrm{CD}^{+} \mathrm{T}$ helper (Th) cells (Mitosek-Szewczyk et al. 2013).

\section{Clinical Studies}

Cladribine showed effectiveness in the phase III placebo-controlled CLARITY trial (Giovannoni et al. 2010). Patients were assigned to cladribine $3.5 \mathrm{mg}$ or $5.25 \mathrm{mg}$ or placebo. The annualized relapse rate (ARR) was significantly lower with $0.14 / 0.15$ in the treatment groups and 0.33 in the placebo group. The risk of disability progression was significantly reduced (hazard ratio [HR] $0.67 / 0.69$, respectively) as well as the brain lesion count on magnetic resonance imaging (MRI). Cladribine treatment was associated with a higher risk of grades 1 and 2 lymphocytopenia $(21.6 \% 3.5 \mathrm{mg}$ group, $31.5 \% 5.25 \mathrm{mg}$ group). Moreover, there was a considerable number of patients who developed herpes zoster (20 in the treatment groups vs. none in the placebo group). The follow-up study, which assessed the long-term effects of cladribine therapy, showed that over a period of 96 weeks, $44 \% /$
$45 \%$ of the patients $(3.5 \mathrm{mg} / \mathrm{kg}, 5.25 \mathrm{mg} / \mathrm{kg}$ group, respectively) were free from disease activity, whereas in the placebo group only $16 \%$ of the patients did not have disease activity (Giovannoni et al. 2011). The ORACLE MS study in patients with a first demyelinating event investigated the potential of cladribine to prevent the conversion to clinically definite MS. Cladribine therapy reduced the risk with a hazard ratio of $0.38(5.25 \mathrm{mg} / \mathrm{kg}$ group $)$ and $0.33(3.5 \mathrm{mg} / \mathrm{kg}$ group) (Leist et al. 2014). Cladribine might also have indirect neuroprotective effects. Further analysis of the CLARITY study revealed that cladribine-treated patients had a reduced rate of percentage brain volume change compared with the placebo group (cladribine, $0.56 \%$ / $0.57 \%, 3.5 \mathrm{mg} / \mathrm{kg} / 5.25 \mathrm{mg} / \mathrm{kg}$ vs. $0.7 \%$ in the placebo group) (De Stefano et al. 2017). More importantly, there was a significant correlation of disability progression with reduced percentage of brain volume change. Long-term effects will have to be evaluated in further studies, as will the question whether the rate of patients progressing might be beneficially altered using cladribine and whether cladribine has a role as induction therapy, with patients stabilized for many years after the initial cycles of cladribine.

\section{Side Effect Profile and Tolerability}

Concerns about the safety profile of cladribine were the reason for stopping the process of authorization by the European Medicines Agency (EMA). Some of the most important serious adverse events of cladribine therapy include myelosuppression and secondary malignancies. In the CLARITY study, the most common adverse events included lymphocytopenia, headache, nasopharyngitis, and upper respiratory tract infection. Serious adverse events included infections with herpes zoster in three of the patients and the occurrence of neoplasms. Those included leiomyomas $(n=5)$, a melanoma and carcinoma of the pancreas and ovary. One death, which occurred in the cladribine treatment group, was because of cardiopulmonary arrest secondary to exacerbation of latent tuberculosis. Although there was a higher number of neoplasms in the treatment group, the authors 
could not establish an enhanced risk for their occurrence as neoplasms were found in several organ systems (Giovannoni et al. 2010). In a meta-analysis of the CLARITY and ORACLE MS trial, no increased risk for neoplasms could be shown (Pakpoor et al. 2015). Data from patients treated for mastocytosis showed especially lymphopenia (82\%), neutropenia (47\%), and opportunistic infections (13\%) (Barete et al. 2015). In the studies conducted in MS, no case of progressive multifocal leukoencephalopathy (PML) occurred, but cladribine therapy has been associated with the development of PML in hematological disorders. Until now, three patients have been reported who have been treated for hairy cell leukemia (Aletti et al. 2011), follicular lymphoma (Berghoff et al. 2013), and systemic mastocytosis (Alstadhaug et al. 2016).

\section{FINGOLIMOD}

Fingolimod (FTY720, brand name Gilenya) is an oral medication that is typically used as escalation therapy. Fingolimod modulates the sphingosine 1-phosphate receptor (S1PR), which leads to internalization and degradation of the receptor. Hence, the ability of autoreactive $\mathrm{T}$ lymphocytes to leave secondary lymphoid organs, especially lymph nodes, is impaired, which leads to reduced influx of lymphocytes into the CNS. In addition to S1PR, other types of S3PR and S5PR are also activated by fingolimod, and it is not yet solved whether this contributes to its therapeutic efficacy.

\section{Mechanisms}

Fingolimod has effects on various tissues that express the S1PR, such as cells of the lymphoid lineage but also microglia, astrocytes, and endothelial cells (Hunter et al. 2016). Astrocytes are important contributors of CNS scar formation and express the S1P3 and S1P1 and also S1P2 to a lesser degree. Fingolimod also has beneficial effects on microglia. Microglia express S1P1 receptors and treatment with FTY leads to reduced release of proinflammatory cytokines, such as TNF- $\alpha$, interleukin (IL)-1 $\beta$, and IL-6 (Noda et al. 2013). Moreover, the production of brain-derived neurotrophic factor (BDNF) and glial cell-derived neurotrophic factor is increased (Noda et al. 2013), suggesting that fingolimod might normalize microglial cytokine release and influence the microglial phenotype. Fingolimod has neuroprotective effects as it reduces excitotoxicity by targeting the p38 MAP kinase (MAPK) stress signaling pathway in microglia (Cipriani et al. 2015). It also ameliorates neurodegenerative processes in the cuprizone model, which is a model of demyelination (Slowik et al. 2015). In the same model, cerebellar remyelination is not influenced (Alme et al. 2015). This could be explained by the finding that fingolimod activates extracellular signalregulated kinase 1/2 and Akt with reduced apoptosis in oligodendrocyte progenitors together with oligodendrocyte differentiation (Coelho et al. 2007). Studies in other neurodegenerative models, such as models of cerebral ischemia, supported neuroprotective effects of fingolimod. In rodent models of cerebral artery occlusion, the infarct size was reduced on treatment with fingolimod accompanied by reduced microglial/ macrophage activation (Wei et al. 2011). Fingolimod did not show direct effects against glutamate excitotoxicity to neurons, suggesting that neuroprotection is mediated rather via anti-inflammatory mechanisms. Neuroprotection was shown also in other models, for example in a rat model of autism (Wu et al. 2017), hemorrhage (Rolland et al. 2017), and Parkinson's disease (Zhao et al. 2017). Hence, it remains unclear whether the neuroprotective effects of fingolimod are linked to its anti-inflammatory properties or whether neuroprotection can be achieved by the medication alone.

\section{Clinical Studies}

Fingolimod had been tested in several phase II and III clinical trials before its approval by the FDA and EMA in 2010. Interestingly, the empirical initial dosing of $5 \mathrm{mg}$ per day could be reduced 10 -fold and still full activity was maintained. The first pivotal study that showed efficacy of fingolimod was the FREEDOMS trial. Here, fingolimod reduced the ARR significantly, either in a dosage of $0.5 \mathrm{mg}$ or in a dosage of 
$1.25 \mathrm{mg}$ compared with placebo (ARR placebo $0.4 ; 0.5 \mathrm{mg}$ fingolimod $0.18 ; 1.25 \mathrm{mg} \mathrm{0.16}$ ) (Kappos et al. 2010). The risk of disability progression was also reduced (HR 0.70 and 0.68 [both dosages] vs. placebo). MRI parameters were significantly better regarding the number of new T2 weighted lesions, gadolinium-enhancing lesions, and brain volume loss. The FREEDOMS II study investigated the effect of fingolimod 0.5 mg or $1.25 \mathrm{mg}$ versus placebo. After a review of other phase III clinical trials, patients in the placebo group were switched to the $0.5 \mathrm{mg}$ group. Treatment with fingolimod reduced the ARR by $48 \%$ but had no effect on percent brain volume change (Table 1) (Calabresi et al. 2014). Owing to the high range of effective doses of fingolimod, a trial with $0.25 \mathrm{mg}$ is still ongoing in North America.

Now, fingolimod has been used for more than 5 years as a therapeutic agent in 160,000 MS patients, hence long-term data get more into the focus of clinicians. Fingolimod has been evaluated in the extension from the randomized TRANSFORMS study, which investigated the effect of switching from IFN- $\beta 1$ a to fingolimod. Switching led to a $50 \%$ reduction of ARR ( 0.4 vs. 0.2 ) concomitant with reduced MRI activity and reduced rate of brain volume loss (Cohen et al. 2016b). Fingolimod might even have neuroprotective effects, as 12-month therapy leads to a significant reduction of neurofilament light-chain levels in the cerebrospinal fluid (CSF) (reduction of $326 \mathrm{pg} / \mathrm{mL}, p=0.002$ ) (Kuhle et al. 2015). However, fingolimod was also tested in a phase III clinical trial in primary progressive MS (PPMS) (oral fingolimod in PPMS [INFORMS]) in which the rate of disease progression was not altered compared with placebo (Lublin et al. 2016). Reasons for the failure of fingolimod are still speculative. Nonetheless, fingolimod might also show neuroprotective properties, as suggested by MRI analyses. De Stefano and colleagues analyzed MRI data from FREEDOMS I and II, and revealed that the percent brain volume change was reduced by $48.2 \%$ after 24 months compared with the placebo control (De Stefano et al. 2016). Using a regression model, they suggested that $54 \%$ of the effect was independent of its effect on visible focal damage, suggesting that both inflammatory and neurodegenerative processes are targeted (Table 2) (De Stefano et al. 2016).

\section{Side Effect Profile and Tolerability}

Fingolimod is relatively well tolerated. One of the most important side effects of the medication includes a reduction of the heart rate, which was 12.4 beats per minute (SD 8.41) in mean (1.25 mg group; maximum) and 8.5 beats per minute (SD 7.84) $5 \mathrm{~h}$ post application of the medication in the FREEDOMS II trial (Calabresi et al. 2014). The percentage of patients with atrioventricular (AV) block I did not differ between treatment and placebo groups and there was no patient with AV block II on treatment. However, there was a higher incidence of Mobitz type I AV block and 2:1 AV block in the fingolimod group. In the FREEDOMS II trial, fingolimod treatment was associated with lymphopenia (8\%, $0.5 \mathrm{mg}$ group; $0 \%$ placebo), increase of the alanine aminotransferase $(8 \%, 0.5$ mg group; $2 \%$ placebo), herpes zoster infection (3\%, $0.5 \mathrm{mg}$ group; $1 \%$ placebo), hypertension (9\%, $0.5 \mathrm{mg}$ group; 3\% placebo), and bradycardia after the administration of the first dose $(1 \%$, $0.5 \mathrm{mg}$ group; $<0.5 \%$ placebo) (Calabresi et al. 2014). The number of serious adverse events was similar in the treatment group (15\%) and the placebo group (13\%) and included basal cell carcinoma (3\% vs. 1\%), macular edema (both $1 \%$ ), infections (3\% vs. $1 \%$ ), and neoplasms (4\% vs. $2 \%$ ) (Calabresi et al. 2014). In the phase IIIb study FIRST, it could be shown that even for patients at risk for cardiac side effects safety precautions with a $6 \mathrm{~h}$ continuous electrocardiogram (ECG) recording are sufficient to avoid severe cardiac side effects (Gold et al. 2014).

Immunosuppression usually raises questions about the ability of the compromised immune system to mount immune responses against novel and recall antigens such as vaccinations. Kappos and colleagues investigated, in a blinded, randomized, multicenter, placebo-controlled trial, the response after influenza vaccination and tetanus toxoid booster dose. Six weeks postvaccination, the response rate was reduced for both influenza vaccination (43\% vs. 
Oral Therapies for MS
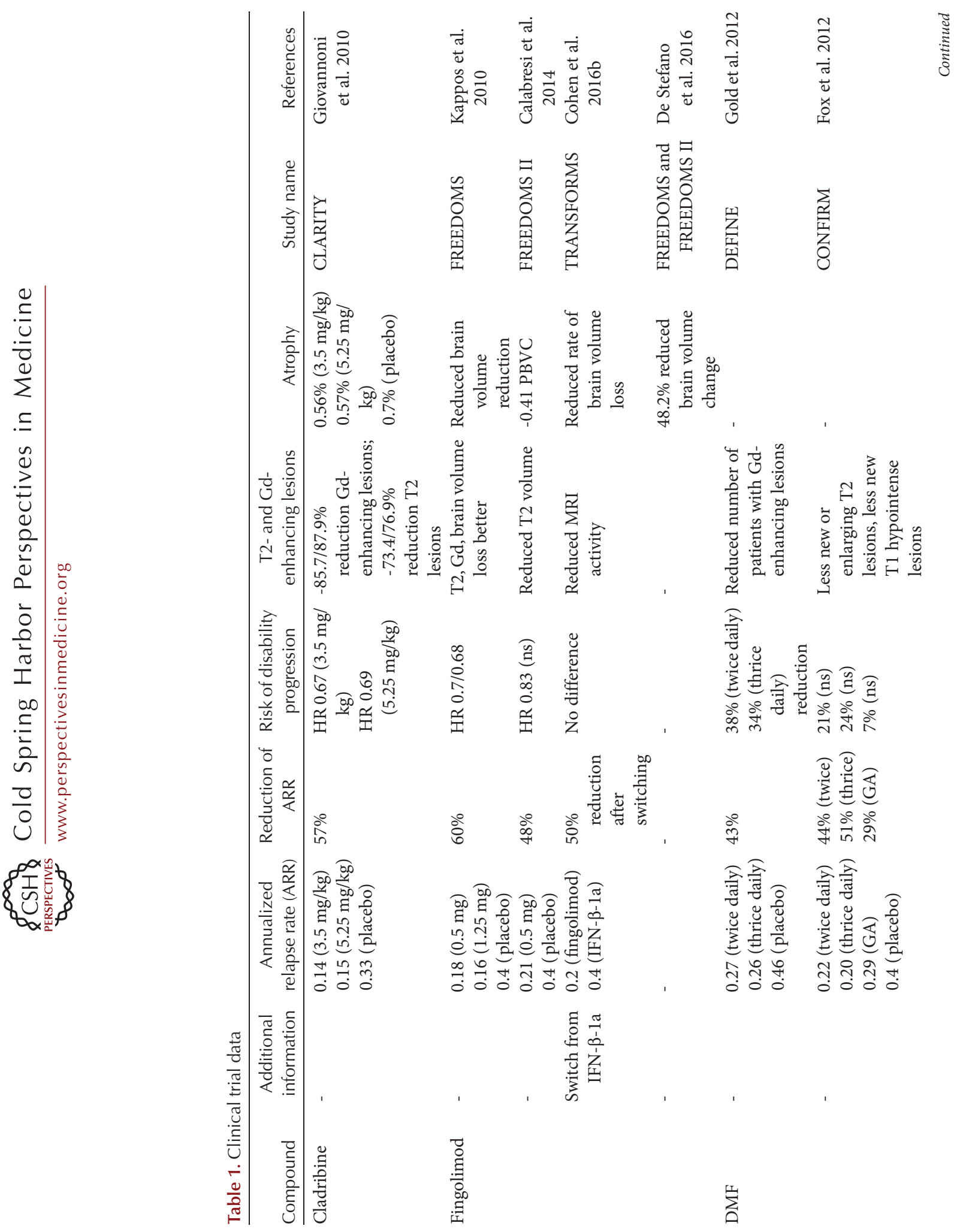
S. Faissner and R. Gold
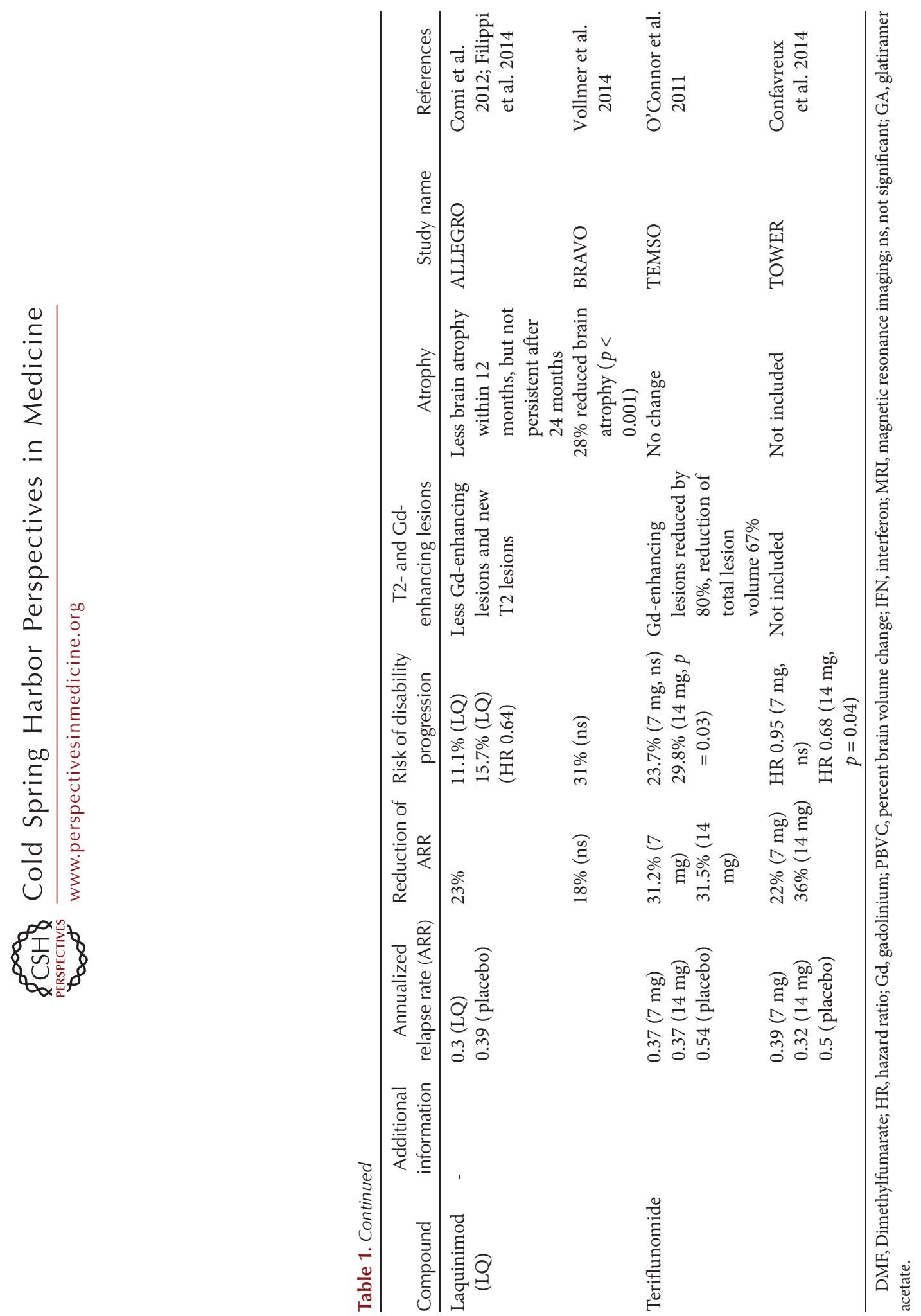
Oral Therapies for MS

Table 2. Risk of conversion from clinically isolated syndrome (CIS) to definite multiple sclerosis (MS)

\begin{tabular}{lllc}
\hline Compound & Risk reduction to develop definite MS & Study & References \\
\hline Cladribine & HR $0.38(5.25 \mathrm{mg} / \mathrm{kg}$ group $)$ & ORACLE MS & Leist et al. 2014 \\
Teriflunomide & HR $0.33(3.5 \mathrm{mg} / \mathrm{kg}$ group $)$ & & \\
\hline
\end{tabular}

HR, Hazard ratio.

$75 \%[0.25 ; 0.11-0.57])$ and tetanus toxoid boostering (38\% vs. $49 \%[0.62 ; 0.29-1.33])$ (Kappos et al. 2015). Thus, although roughly $40 \%$ of the patients were able to mount an immune response against vaccination, the response was not as strong as in the placebo group.

Currently, three more selective S1P agonists are in their final stage of study evaluation: ponesimod, ozanimod, and siponimod. Siponimod is currently investigated in the phase II BOLD study (NCT00879658) and the phase III EXPAND trial (NCT01665144). Ozanimod is investigated in the phase II/III RADIANCE (NCT01628393) and phase III SUNBEAM trial (NCT02294058). Ponesimod is investigated in the phase III OPTIMUM (NCT02425644) and POINT trials (NCT02907177). Those molecules have shorter half-lives than fingolimod and are reported to lead to a faster recovery of lymphocyte counts after discontinuation of treatment (Selmaj et al. 2013; Olsson et al. 2014; Cohen et al. 2016a). Whether they offer a superior profile compared with fingolimod or just imitate the prototype fingolimod is currently unclear.

\section{BG-12, DIMETHYLFUMARATE}

Fumarates were first introduced as therapeutics for the treatment of psoriasis as Fumaderm containing 56\% DMF (120 mg) and 44\% ethylhydrogenfumarate (95 $\mathrm{mg}$ of three different salts). The first anecdotal reports about coincidental amelioration of MS in psoriasis patients treated with Fumaderm led to a prospective clinical observation of ten RRMS patients treated with fumarates over 72 weeks (Schimrigk et al. 2006).

\section{Immunomodulatory Mechanisms of DMF}

DMF has pleiotropic effects on immune cells, glia, and neurons as it induces immunomodula- tion on different immune cell subsets and shows cytoprotective properties. Fumaric acid esters are able to modify the expression of genes involved in antioxidative mechanisms. Monomethylfumarate (MMF), which is the active metabolite of DMF, modifies the Kelch-like erythroid cell-derived associated protein-1 (KEAP-1) via binding. In turn, this leads to modification of the KEAP-1/nuclear factor (erythroid-derived 2)like 2 (Nrf2) complex. The translocation of Nrf2 to the nucleus modifies the transcription of antioxidative genes, ultimately promoting cytoprotective effects in chronic EAE (Linker et al. 2011). In a later study conducted in acute EAE $\mathrm{Nrf}^{-1-} \mathrm{C} 57 \mathrm{BL} / 6$ mice were still protected on treatment with DMF (Schulze-Topphoff et al. 2016), suggesting more pathways to be active. DMF induced a reduction of circulation IFN- $\gamma$ and IL-17 producing $\mathrm{CD}^{+}$cells and induced anti-inflammatory M2 monocytes (SchulzeTopphoff et al. 2016). The investigators discussed that neuroprotective effects, which are important to prevent chronification, are rather mediated by Nrf2, whereas immunomodulation in the acute phase seems to be mediated by a shift of the immune cell composition. Immunomodulation was also shown ex vivo in DMF-treated patients, as analyses of T-cell subsets showed a shift to a Th2 cell type on DMF treatment (Gross et al. 2016). DMF also influences B-cell subsets. In patients with RRMS, DMF treatment decreased the number of circulating mature/differentiated B cells, mostly on memory rather than naïve B cells ( $\mathrm{Li}$ et al. 2017). This was accompanied by a shift of the cytokine profile to an antiinflammatory phenotype. DMF reduces the release of proinflammatory cytokines in activated microglia and rescues mitochondrial deficits in neurons (Peng et al. 2016). DMF modulates microglia through the activation of the HCAR2 pathway, which leads to the modulation of neu- 
roinflammation and restores synaptic alterations in EAE (Parodi et al. 2015). The combination with IFN- $\beta$ even shows enhanced neuroprotection in EAE (Reick et al. 2014).

There is also evidence that DMF might have beneficial effects in other models of autoimmunity or neurodegeneration. Pitarokoili et al. (2015) showed clinical improvement in conjunction with less demyelination and axonal degeneration in experimental autoimmune neuritis (EAN), a model of Guillain-Barré syndrome (GBS). Another EAN study showed a shift of macrophage phenotypes with less proinflammatory M1 macrophages and more anti-inflammatory M2 macrophages (Han et al. 2016). This was accompanied by reduced messenger RNA (mRNA) of IFN- $\gamma$, TNF- $\alpha$, IL- 6 , and IL-17 and up-regulation of anti-inflammatory IL-4 and IL-10 (Han et al. 2016). The anti-inflammatory properties of DMF might also support neuroprotection as DMF treatment ameliorates locomotor function in a model of spinal cord injury in conjunction with increases of neurotrophic factors BDNF, glial-derived neurotrophic factor (GDNF), and neurotrophin 3 (NT-3) (Cordaro et al. 2016). DMF inhibits the activation of neutrophils, the ability to produce reactive oxygen species, and phagocytic activity, which might be of interest in neutrophil-mediated diseases such as epidermolysis bullosa (Muller et al. 2016). In summary, DMF modulates immune cells to a protective phenotype and shows antioxidative and neuroprotective properties.

\section{Clinical Studies}

Efficacy of fumarates in MS was shown the first time in a small open-label observation with ten patients (Schimrigk et al. 2006). This was followed by large phase III clinical trials. The DEFINE trial compared BG-12 $240 \mathrm{mg}$ twice or thrice daily to placebo (Gold et al. 2012). The study showed a significant reduction of relapses ( $41 \% / 43 \%$ reduction of ARR in the twice, thrice daily group, respectively). The proportion of patients with confirmed disability progression was reduced by $38 \% / 34 \%$, respectively, compared with placebo. This was corroborated by a reduced number of patients with gadolinium-en- hancing lesions (90/73\%) and new/enlarging T2 lesions (85/74\%). Data about the clinical and paraclinical efficacy of DMF were reproduced in the CONFIRM study (Fox et al. 2012). Differing from the DEFINE study, the CONFIRM study also investigated the comparison to glatiramer acetate as active treatment arm only powered against placebo. In CONFIRM, significant differences could be shown for the ARR (BG-12 thrice daily), new T2 lesions, and new T1 lesions. Those two studies were the basis for the approval of the FDA and EMA. The ongoing extension of the DEFINE/CONFIRM studies, ENDORSE, which was conducted over 5 years, showed continuous low ARR $(0.202,0.163$, $0.139,0.143$, and 0.138 (years $1-5$, respectively) and low rates of new gadolinium-enhancing lesions (Gold et al. 2016a).

Because of the aforementioned antioxidative effects with cytoprotective and neuroprotective properties, the medication was also tested in PPMS. In a small observational study in 26 patients treated with Fumaderm $(n=18)$ or DMF $(n=8), 75 \%$ of the patients either remained stable or slightly ameliorated (Strassburger-Krogias et al. 2014). In November 2016, the "Dimethyl Fumarate Treatment of Primary Progressive Multiple Sclerosis" (FUMAPMS) phase II clinical trial investigating DMF in patients with PPMS started at Copenhagen MS Center (ClinicalTrials.gov; identifier: NCT029 59658; the estimated study completion is December 2019). The primary outcome of the study will be neurofilament heavy chain as a marker of neurodegeneration.

\section{Side Effect Profile and Tolerability}

The phase III clinical trials and real-world data from the past years have shown a good safety and side effect profile for DMF. DMF treatment is related to significantly more gastrointestinal side effects such as diarrhea, nausea, and upper abdominal pain. In addition, patients report about flushes, which occur usually within the first hour after drug intake. Those can be resolved by intake of aspirin. PML, one of the most feared side effects of immunomodulatory substances, has been reported until now in five 
patients out of 230,000, which have been treated with DMF. The first patient had long-term lymphocytopenia with lymphocyte counts of 290580 cells $\mathrm{mm}^{-3}$ over a period of 3.5 years, with unfortunately a fatal outcome (Rosenkranz et al. 2015). In the studies about DMF in RRMS lymphocytes dropped on average about $30 \%$ and only a small proportion of $2 \%$ had counts $<500$ cells $\mathrm{mm}^{-3}$ (Fox et al. 2016). In addition, several patients that have been treated with Fumaderm for psoriasis have been diagnosed with PML (Ermis et al. 2013; van Oosten et al. 2013; Stoppe et al. 2014; Hoepner et al. 2015; Nieuwkamp et al. 2015). In one patient who had negative John Cunningham virus (JCV)-DNA in the CSF, a brain biopsy revealed typical histopathological alterations for PML and JCV-positive neurons (Bartsch et al. 2015). In this patient, total lymphocyte counts were not altered but analysis of lymphocyte subsets documented reduced $\mathrm{CD} 8^{+}$ T-cell subsets, which might be involved in PML pathology (Bartsch et al. 2015). An overall age above 50 years and an early drop of lymphocytes in the first 6 months are associated with an increased risk for PML.

Summarizing, DMF is a safe and relatively well-tolerated medication with a strong effect on ARR and neuroprotective properties. Larger trials have to prove whether the medication might also be effective in progressive MS. Follow-up developments such as XP28829 and ALKS8700 offer different fumarate compounds with putatively reduced gastrointestinal side effects. ALKS8700 is an aminoethyl ester of MMF, which is rapidly converted to MMF (Naismith et al. 2016) and is currently investigated in the phase III EVOLVE-MS-1 study (NCT02634307). Especially, gastrointestinal side effects were lower in a phase I study compared with DMF treatment (8.3\% vs. $41.7 \%$ ) (Naismith et al. 2016).

\section{LAQUINIMOD}

\section{Mechanism of Action}

Laquinimod is an orally available quinoline-3carboxamide, which is under development as therapeutic for RRMS, PPMS, and Huntington's disease. Laquinimod gets readily into the CNS, achieving $7 \%$ of the blood concentration (measured in healthy rats) (Brück and Wegner 2011). Laquinimod showed first efficacy in EAE with reduction of clinical signs, inflammation, and demyelination (Wegner et al. 2010). This was accompanied by down-regulation of IL-17. Within lesions, axonal damage was also reduced, hence providing early evidence that the molecule might show neuroprotective properties. Preclinical and clinical data proved that laquinimod has effects on various immune cells. Laquinimod reduces $\mathrm{CD} 11 \mathrm{c}^{+} \mathrm{CD} 4^{+}$dendritic cells, inhibits the expansion of $\mathrm{T}$ cells, and suppresses the formation of germinal center B cells, hence reducing disability progression in spontaneous EAE in the 2D2 model (Varrin-Doyer et al. 2016). Laquinimod also modifies the phenotype of B cells with an up-regulation of regulatory molecules CD25, IL-10, and CD86 in accordance with decreased IL-4 and increased transforming growth factor $\beta$ (TGF- $\beta$ ) (Toubi et al. 2012). Early studies investigated the question whether the effect might be mediated by IFN- $\beta$. Taking advantage of IFN- $\beta$ knockout mice, it could be excluded that the effect in EAE is mediated by IFN- $\beta$ (Runstrom et al. 2006). The presence of high-affinity BDNF receptors is clearly linked to the activity of the drug (Thone et al. 2012). The immunomodulatory effect of laquinimod is mediated by the aryl hydrocarbon receptor, whereas neuroprotective effects of the medication are maybe mediated via other mechanisms (Berg et al. 2016). Laquinimod reduces the number of dendritic cells in the blood as well and alters their maturation (Jolivel et al. 2013). This effect is mediated by inhibition of nuclear factor (NF)- $\mathrm{\kappa B}$ signaling (Jolivel et al. 2013). EAE data indicate that laquinimod also inhibits proinflammatory monocytes to enter the CNS, hence reducing spinal cord inflammation with reduced CD62L and matrix metalloproteinase (MMP)-9 (Mishra et al. 2012).

Possible neuroprotective effects of the medication are supported by reports about efficacy in a model of Huntington's disease, the YAC128 model. Here, striatal and cortical atrophy could be rescued in accordance with improvement of motor function and depressive-like behavior (Garcia-Miralles et al. 2016). Neuroprotective 
properties are mediated by the inhibition of the Bax pathway, which is involved in apoptosis, hence leading to reduced caspase- 6 activity in neurons (Ehrnhoefer et al. 2016). Laquinimod also has effects in the cuprizone model, which is a model of demyelination. Laquinimod treatment reduces axonal spheroid formation, activation of microglia/macrophages, and apoptosis of oligodendrocytes together with reduced demyelination (Kramann et al.2016). Brücketal. (2012) showed that this is mediated by reduced NF- $\kappa B$ signaling in astrocytes. In EAN, laquinimod exerted positive clinical effects within a small-dose range in accordance with less demyelination and inflammation (Pitarokoili et al. 2014).

\section{Clinical Studies}

The clinical studies conducted so far show inconsistent results. In the ALLEGRO phase III clinical trial, laquinimod significantly reduced the ARR by $23 \%$ from 0.39 in the placebo group to 0.3 in the laquinimod arm (Comi et al. 2012). The risk of disability progression was also reduced (11.1\% vs. 15.7\%). Laquinimod especially showed promising results regarding brain atrophy in this trial. After 12 months, the rate of atrophy in several brain regions was reduced on laquinimod treatment (Filippi et al. 2014). This effect persisted, however, not up to 24 months. In a follow-up study, the BRAVO phase III clinical trial, laquinimod $0.6 \mathrm{mg}$ once daily did not differ from placebo regarding the ARR and also failed regarding disability progression (Vollmer et al. 2014). However, laquinimod had a significant effect on the reduction of brain atrophy. Blood samples of laquinimod-treated MS patients had increased levels of BDNF, which might explain in part the neuroprotective properties of the medication. Thus, laquinimod showed inconsistent results regarding measures of inflammation but good effects on MRI parameters of brain atrophy. Therefore, the medication might be interesting as a treatment option for progressive MS.

Currently, laquinimod is investigated in the CONCERTO trial in RRMS (NCT01707992) and ARPEGGIO in PPMS. In January 2016, the higher dosage arms of 1.2 or 1.5 laquinimod were stopped in both trials because of cardiac events, reminiscent of the mother drug linomide, which induced coronary vasculitis as an unwanted side effect. Results from CONCERTO are expected in April 2017 and for ARPEGGIO in October 2017.

\section{Side Effect Profile and Tolerability}

Apart from the aforementioned cardiac side effects in the two ongoing trials, laquinimod was well tolerated in the studies that have been completed so far. The ALLEGRO trial showed an increased risk for alanine transaminase elevation of more than three times more than the upper limit by 2.6-fold compared with placebo. The elevations were of transient nature and not associated with clinical, imaging, or laboratory signs of liver failure (Comi et al. 2012). In the BRAVO trial, the most important side effects included headache (3\%), increased alanine transaminase (2\%), and nausea (0.4\%) (Vollmer et al. 2014). No clear signs for coagulation disorders were observed.

\section{TERIFLUNOMIDE}

Teriflunomide was approved as oral therapy for RRMS in September 2012 (FDA) in a dosage of $14 \mathrm{mg}$ per day. The compound is the active metabolite of leflunomide, which has been used for the treatment of rheumatoid arthritis after approval in the European Union in 1998 (ARAVA, Sanofi-Aventis). Teriflunomide leads to the inhibition of the dihydroorotate dehydrogenase (DHODH), hence inhibiting the proliferation of activated lymphocytes (Cherwinski et al. 1995; Ringshausen et al. 2008). As there exists a DHODH-independent salvage pathway, established immune responses are not impaired and neuronal cells do not suffer from pyrimidine deficiency.

\section{Mechanism of Action}

Teriflunomide inhibits the dihydroorotate dehydrogenase, which leads to reduced proliferation of B cells and T cells without inducing cytotoxicity (Li et al. 2013). The molecule also reduces 
the release of proinflammatory cytokines IL-6, IL-8, and MCP-1 from peripheral blood mononuclear cells (PBMCs) (Li et al. 2013). This effect was not reversible by the addition of exogenous uridine. Teriflunomide showed effectiveness in several in vivo models. In EAE in Dark Agouti rats, the medication reduced clinical signs accompanied by less infiltration of T cells, macrophages, natural killer cells, and neutrophils (Ringheim et al. 2013). Teriflunomide also shows beneficial effects on glial cells in vitro. It reduces proliferation of microglia by about 30\% in a concentration of $5 \mu \mathrm{M}$ in vitro, enhances the expression of IL-10 (Wostradowski et al. 2016), and modulates microglial-monocyte interaction in HIV infection with improved neurotoxicity (Ambrosius et al. 2017). Interestingly, leflunomide can inhibit viral replication (Teschner et al. 2009; Bernhoff et al. 2010), which speaks for safety in terms of opportunistic infections.

\section{Clinical Studies}

The effectiveness of teriflunomide has been proven in three phase III placebo-controlled clinical trials (O'Connor et al. 2011; Confavreux et al. 2014; Miller et al. 2014). In TEMSO, 1088 patients were included and randomized into three arms (teriflunomide 7 or $14 \mathrm{mg}$, placebo). The ARR was reduced by $31.2 \%$ and $31.5 \%$, respectively (7 and $14 \mathrm{mg}$ group, respectively). Disability progression was reduced by $30 \%$ (O'Connor et al. 2011). MRI parameters also showed improvement compared with placebo. The number of T1 gadolinium-enhancing lesions was reduced by $80 \%$; the total lesion volume was reduced by $67 \%$.

In TOWER, 1169 patients were included and randomized in the same manner as in the TEMSO trial. Data about effectiveness were comparable with a $36 \%$ reduction of the ARR and a reduced progression of disability (HR 0.68; $14 \mathrm{mg}$ group) (Confavreux et al. 2014). The TOPIC study investigated 618 patients with a clinically isolated syndrome and the risk to convert to a clinical definite MS. Treatment with teriflunomide led to a significant risk reduction for the occurrence of a second demyelinating event (HR 0.65) (Miller et al. 2014).
Teriflunomide was also investigated in CIS in the TOPIC trial. Here, teriflunomide reduced the risk of a relapse or a new MRI lesion at both dosages $14 \mathrm{mg}$ (HR 0.651 [95\% CI 0.515-0.822]; $p=0.0003)$ and $7 \mathrm{mg}(0.686$ [0.540-0.871]; $p=$ $0.0020)$. More recently, the phase IV Teri-PRO study focusing on patient reported outcomes reinforced the clinical value of teriflunomide (Gold et al. 2016b).

\section{Side Effect Profile and Tolerability}

There exists long-term experience with teriflunomide regarding safety and side effects of the compound. The extension of the pivotal phase III TEMSO trial followed 742 patients (O'Connor et al. 2016). At the time point of publication, the compound was well tolerated with continued exposure. Patients treated with teriflunomide encounter elevations of liver function enzymes with an increase of the alanine transaminase of $>1$ times higher than normal (54.0\% and 57.3\% [7 $\mathrm{mg}$ and $14 \mathrm{mg}$ group, respectively] compared to $35.9 \%$ in the placebo group). The percentage of patients with increases of ALT $>3$ times the upper limit did not differ. Teriflunomide-treated patients had significantly more gastrointestinal symptoms such as nausea and diarrhea. Another considerable side effect is alopecia/hair thinning, which has been reported in $13.9 \%$ of teriflunomide-treated patients compared to $5.1 \%$ in the placebo group. Neoplasms were not reported on teriflunomide treatment. In $1 \%-2 \%$ of patients, a sensory neuropathy developed. Mounting an immune response after a vaccination is an important consideration for the treatment with immunosuppressive therapies. A small study conducted in patients treated with teriflunomide in both dosages and IFN- $\beta$ showed that $61 \%$ in the $14 \mathrm{mg}$ group were able to mount an immune response against seasonal influenza (Bar-Or et al. 2013). The response of the $7 \mathrm{mg}$ group (78\%) was comparable to the group treated with IFN- $\beta 1(82 \%)$.

\section{CONCLUDING REMARKS}

During the last decade, the armamentarium of MS therapies has considerably grown. Nowadays 
it is possible to choose from a group of several injectables and compounds that are available as oral formulations. Monoclonal antibodies, used for therapy escalation together with fingolimod and reviewed elsewhere, complement the treatment possibilities. Oral therapeutics satisfy the need of patients to use medications with a pleasant way of administration although they do not enhance the adherence to therapy compared with injectables (Munsell et al. 2017). However, one of the biggest advantages with the growing armamentarium of therapeutic possibilities is that it is now possible to stratify for the optimal treatment regime before starting an immunomodulatory therapy based on knowledge about other underlying autoimmune conditions. For instance, it might be worthwhile to treat a patient with coincidental psoriasis with DMF or another patient with rheumatoid arthritis with teriflunomide. Another considerable advantage of modern MS therapy is the possibility to switch treatments without having to escalate in case the first oral therapeutic does not stabilize the disease or patients want to withdraw because of side effects. One of the biggest unmet needs of MS therapy is progression, which is up to now without authorized treatment options. Preclinical data about some of the molecules reviewed here are promising in the sense that neuroprotection might be feasible in progressive MS. In case laquinimod gets authorization for RRMS, the therapeutic armamentarium will grow even further and provide clinicians with more options for oral MS therapy.

\section{REFERENCES}

Aletti M, Faivre A, Wybrecht D, Couturier C, Bounolleau P, Alla P. 2011. Progressive multifocal leukoencephalopathy after cladribine treatment for hairy cell leukemia. Neurology 76: A28.

Alme MN, Nystad AE, Bo L, Myhr KM, Vedeler CA, Wergeland S, Torkildsen O. 2015. Fingolimod does not enhance cerebellar remyelination in the cuprizone model. J Neuroimmunol 285: 180-186.

Alstadhaug KB, Fykse Halstensen R, Odeh F. 2016. Progressive multifocal leukoencephalopathy in a patient with systemic mastocytosis treated with cladribine. J Clin Virol 88: $17-20$.

Ambrosius B, Faissner S, Guse K, von Lehe M, Grunwald T, Gold R, Grewe B, Chan A. 2017. Teriflunomide and monomethylfumarate target HIV-induced neuroinflammation and neurotoxicity. J Neuroinflamm 14: 51.

Barete S, Lortholary O, Damaj G, Hirsch I, Chandesris MO, Elie C, Hamidou M, Durieu I, Suarez F, Grosbois B, et al. 2015. Long-term efficacy and safety of cladribine (2-CdA) in adult patients with mastocytosis. Blood 126: 10091016; quiz 1050.

Bar-Or A, Freedman MS, Kremenchutzky M, Menguy-Vacheron F, Bauer D, Jodl S, Truffinet P, Benamor M, Chambers S, O'Connor PW. 2013. Teriflunomide effect on immune response to influenza vaccine in patients with multiple sclerosis. Neurology 81: 552-558.

Bartsch T, Rempe T, Wrede A, Leypoldt F, Brück W, Adams O, Rohr A, Jansen O, Wuthrich C, Deuschl G, et al. 2015. Progressive neurologic dysfunction in a psoriasis patient treated with dimethyl fumarate. Ann Neurol 78: 501-514.

Berg J, Mahmoudjanlou Y, Duscha A, Massa MG, Thone J, Esser C, Gold R, Haghikia A. 2016. The immunomodulatory effect of laquinimod in CNS autoimmunity is mediated by the aryl hydrocarbon receptor. J Neuroimmunol 298: 9-15.

Berghoff M, Schanzer A, Hildebrandt GC, Dassinger B, Klappstein G, Kaps M, Gizewski ER, Acker T, Grams A. 2013. Development of progressive multifocal leukoencephalopathy in a patient with non-Hodgkin lymphoma 13 years after treatment with cladribine. Leukemia Lymphoma 54: 1340-1342.

Bernhoff E, Tylden GD, Kjerpeseth LJ, Gutteberg TJ, Hirsch HH, Rinaldo CH. 2010. Leflunomide inhibition of BK virus replication in renal tubular epithelial cells. J Virol 84: $2150-2156$.

Beutler E. 1992. Cladribine (2-chlorodeoxyadenosine). Lancet 340: 952-956.

Brück W, Wegner C. 2011. Insight into the mechanism of laquinimod action. J Neurol Sci 306: 173-179.

Brück W, Pfortner R, Pham T, Zhang J, Hayardeny L, Piryatinsky V, Hanisch UK, Regen T, van Rossum D, Brakelmann L, et al. 2012. Reduced astrocytic NF- $\kappa B$ activation by laquinimod protects from cuprizone-induced demyelination. Acta Neuropathol 124: 411-424.

Calabresi PA, Radue EW, Goodin D, Jeffery D, Rammohan KW, Reder AT, Vollmer T, Agius MA, Kappos L, Stites T, et al. 2014. Safety and efficacy of fingolimod in patients with relapsing-remitting multiple sclerosis (FREEDOMS II): A double-blind, randomised, placebo-controlled, phase 3 trial. Lancet Neurol 13: 545-556.

Cherwinski HM, Cohn RG, Cheung P, Webster DJ, Xu YZ, Caulfield JP, Young JM, Nakano G, Ransom JT. 1995. The immunosuppressant leflunomide inhibits lymphocyte proliferation by inhibiting pyrimidine biosynthesis. $J$ Pharmacol Exp Therapeut 275: 1043-1049.

Cipriani R, Chara JC, Rodriguez-Antiguedad A, Matute C. 2015. FTY720 attenuates excitotoxicity and neuroinflammation. J Neuroinflamm 12: 86.

Coelho RP, Payne SG, Bittman R, Spiegel S, Sato-Bigbee C. 2007. The immunomodulator FTY720 has a direct cytoprotective effect in oligodendrocyte progenitors. J Pharmacol Exp Therapeut 323: 626-635.

Cohen JA, Arnold DL, Comi G, Bar-Or A, Gujrathi S, Hartung JP, Cravets M, Olson A, Frohna PA, Selmaj KW. 2016a. Safety and efficacy of the selective sphingosine 1phosphate receptor modulator ozanimod in relapsing 
multiple sclerosis (RADIANCE): A randomised, placebocontrolled, phase 2 trial. Lancet Neurol 15: 373-381.

Cohen JA, Khatri B, Barkhof F, Comi G, Hartung HP, Montalban X, Pelletier J, Stites T, Ritter S, von Rosenstiel P, et al. 2016b. Long-term (up to 4.5 years) treatment with fingolimod in multiple sclerosis: Results from the extension of the randomised TRANSFORMS study. J Neurol Neurosurg Psychiatry 87: 468-475.

Comi G, Jeffery D, Kappos L, Montalban X, Boyko A, Rocca MA, Filippi M. 2012. Placebo-controlled trial of oral laquinimod for multiple sclerosis. N Engl J Med 366: 1000 1009.

Confavreux C, O'Connor P, Comi G, Freedman MS, Miller AE, Olsson TP, Wolinsky JS, Bagulho T, Delhay JL, Dukovic D, et al. 2014. Oral teriflunomide for patients with relapsing multiple sclerosis (TOWER): A randomised, double-blind, placebo-controlled, phase 3 trial. Lancet Neurol 13: 247-256.

Cordaro M, Casili G, Paterniti I, Cuzzocrea S, Esposito E. 2016. Fumaric acid esters attenuate secondary degeneration following spinal cord injury. J Neurotrauma 34: 3027-3040.

De Stefano N, Tomic D, Radue EW, Sprenger T, Meier DP, Haring D, Sormani MP. 2016. Effect of fingolimod on diffuse brain tissue damage in relapsing-remitting multiple sclerosis patients. Mult Scler Relat Disord 7: 98-101.

De Stefano N, Giorgio A, Battaglini M, De Leucio A, Hicking C, Dangond F, Giovannoni G, Sormani MP. 2017. Reduced brain atrophy rates are associated with lower risk of disability progression in patients with relapsing multiple sclerosis treated with cladribine tablets. Mult Scler doi: $10.1177 / 1352458517690269$.

Ehrnhoefer DE, Caron NS, Deng Y, Qiu X, Tsang M, Hayden MR. 2016. Laquinimod decreases Bax expression and reduces caspase-6 activation in neurons. Exp Neurol 283: $121-128$.

Ermis U, Weis J, Schulz JB. 2013. PML in a patient treated with fumaric acid. N Engl J Med 368: 1657-1658.

Filippi M, Rocca MA, Pagani E, De Stefano N, Jeffery D, Kappos L, Montalban X, Boyko AN, Comi G. 2014. Placebo-controlled trial of oral laquinimod in multiple sclerosis: MRI evidence of an effect on brain tissue damage. $J$ Neurol Neurosurg Psychiatry 85: 851-858.

Fox RJ, Miller DH, Phillips JT, Hutchinson M, Havrdova E, Kita M, Yang M, Raghupathi K, Novas M, Sweetser MT, et al. 2012. Placebo-controlled phase 3 study of oral BG-12 or glatiramer in multiple sclerosis. $N$ Engl J Med 367: 1087-1097.

Fox RJ, Coffey CS, Cudkowicz ME, Gleason T, Goodman A, Klawiter EC, Matsuda K, McGovern M, Conwit R, Naismith R, et al. 2016. Design, rationale, and baseline characteristics of the randomized double-blind phase II clinical trial of ibudilast in progressive multiple sclerosis. Contemp Clin Trials 50: 166-177.

Garcia-Miralles M, Hong X, Tan LJ, Caron NS, Huang Y, To XV, Lin RY, Franciosi S, Papapetropoulos S, Hayardeny L, et al. 2016. Laquinimod rescues striatal, cortical and white matter pathology and results in modest behavioural improvements in the YAC128 model of Huntington disease. Sci Rep 6: 31652 .

Giovannoni G, Comi G, Cook S, Rammohan K, Rieckmann P, Soelberg Sorensen P, Vermersch P, Chang P, Hamlett
A, Musch B, et al. 2010. A placebo-controlled trial of oral cladribine for relapsing multiple sclerosis. $N$ Engl J Med 362: 416-426.

Giovannoni G, Cook S, Rammohan K, Rieckmann P, Sorensen PS, Vermersch P, Hamlett A, Viglietta V, Greenberg S. 2011. Sustained disease-activity-free status in patients with relapsing-remitting multiple sclerosis treated with cladribine tablets in the CLARITY study: A post-hoc and subgroup analysis. Lancet Neurol 10: 329-337.

Gold R, Kappos L, Arnold DL, Bar-Or A, Giovannoni G, Selmaj K, Tornatore C, Sweetser MT, Yang M, Sheikh SI, et al. 2012. Placebo-controlled phase 3 study of oral BG-12 for relapsing multiple sclerosis. N Engl J Med 367: 1098-1107.

Gold R, Comi G, Palace J, Siever A, Gottschalk R, Bijarnia M, von Rosenstiel P, Tomic D, Kappos L. 2014. Assessment of cardiac safety during fingolimod treatment initiation in a real-world relapsing multiple sclerosis population: A phase 3b, open-label study. J Neurol 261: 267-276.

Gold R, Arnold DL, Bar-Or A, Hutchinson M, Kappos L, Havrdova E, MacManus DG, Yousry TA, Pozzilli C, Selmaj K, et al. 2016a. Long-term effects of delayed-release dimethyl fumarate in multiple sclerosis: Interim analysis of ENDORSE, a randomized extension study. Mult Scler 23: 253-265.

Gold R, Schlegel E, Elias-Hamp B, Albert C-O, Schmidt S, Tackenberg B, Potts J, Schaak T, Salmen HC. 2016b. Incidence and mitigation of gastrointestinal events in patients with relapsing-remitting multiple sclerosis receiving dimethyl fumarate-A German phase IV study (TOLERATE). ECTRIMS Online Library P1663.

Gross CC, Schulte-Mecklenbeck A, Klinsing S, Posevitz-Fejfar A, Wiendl H, Klotz L. 2016. Dimethyl fumarate treatment alters circulating $\mathrm{T}$ helper cell subsets in multiple sclerosis. Neurol Neuroimmunol Neuroinflamm 3: e183.

Han R, Xiao J, Zhai H, Hao J. 2016. Dimethyl fumarate attenuates experimental autoimmune neuritis through the nuclear factor erythroid-derived 2-related factor 2/ hemoxygenase-1 pathway by altering the balance of M1/M2 macrophages. J Neuroinflamm 13: 97.

Hoepner R, Faissner S, Klasing A, Schneider R, Metz I, Bellenberg B, Lukas C, Altmeyer P, Gold R, Chan A. 2015. Progressive multifocal leukoencephalopathy during fumarate monotherapy of psoriasis. Neurol Neuroimmunol Neuroinflamm 2: e85.

Hunter SF, Bowen JD, Reder AT. 2016. The direct effects of fingolimod in the central nervous system: Implications for relapsing multiple sclerosis. CNS Drugs 30: 135-147.

Jolivel V, Luessi F, Masri J, Kraus SH, Hubo M, Poisa-Beiro L, Klebow S, Paterka M, Yogev N, Tumani H, et al. 2013. Modulation of dendritic cell properties by laquinimod as a mechanism for modulating multiple sclerosis. Brain 136: 1048-1066.

Kappos L, Radue EW, O'Connor P, Polman C, Hohlfeld R, Calabresi P, Selmaj K, Agoropoulou C, Leyk M, ZhangAuberson L, et al. 2010. A placebo-controlled trial of oral fingolimod in relapsing multiple sclerosis. $N$ Engl J Med 362: $387-401$.

Kappos L, Mehling M, Arroyo R, Izquierdo G, Selmaj K, Curovic-Perisic V, Keil A, Bijarnia M, Singh A, von Rosenstiel P. 2015. Randomized trial of vaccination in fingo- 
limod-treated patients with multiple sclerosis. Neurology 84: $872-879$.

Kramann N, Menken L, Hayardeny L, Hanisch UK, Brück W. 2016. Laquinimod prevents cuprizone-induced demyelination independent of Toll-like receptor signaling. Neurol Neuroimmunol Neuroinflamm 3: e233.

Kraus SH, Luessi F, Trinschek B, Lerch S, Hubo M, PoisaBeiro L, Paterka M, Jonuleit H, Zipp F, Jolivel V. 2014 Cladribine exerts an immunomodulatory effect on human and murine dendritic cells. Int Immunopharmacol 18: $347-357$

Kuhle J, Disanto G, Lorscheider J, Stites T, Chen Y, Dahlke F Francis G, Shrinivasan A, Radue EW, Giovannoni G, et al. 2015. Fingolimod and CSF neurofilament light chain levels in relapsing-remitting multiple sclerosis. Neurology 84: 1639-1643.

Leist TP, Comi G, Cree BA, Coyle PK, Freedman MS, Hartung HP, Vermersch P, Casset-Semanaz F, Scaramozza M 2014. Effect of oral cladribine on time to conversion to clinically definite multiple sclerosis in patients with a first demyelinating event (ORACLE MS): A phase 3 randomised trial. Lancet Neurol 13: 257-267.

Li L, Liu J, Delohery T, Zhang D, Arendt C, Jones C. 2013. The effects of teriflunomide on lymphocyte subpopulations in human peripheral blood mononuclear cells in vitro. J Neuroimmunol 265: 82-90.

Li R, Rezk A, Ghadiri M, Luessi F, Zipp F, Li H, Giacomini PS, Antel J, Bar-Or A. 2017. Dimethyl fumarate treatment mediates an anti-inflammatory shift in B cell subsets of patients with multiple sclerosis. J Immunol 198: 691-698.

Linker RA, Lee DH, Ryan S, van Dam AM, Conrad R, Bista P, Zeng W, Hronowsky X, Buko A, Chollate S, et al. 2011. Fumaric acid esters exert neuroprotective effects in neuroinflammation via activation of the $\mathrm{Nrf} 2$ antioxidant pathway. Brain 134: 678-692.

Lublin F, Miller DH, Freedman MS, Cree BA, Wolinsky JS, Weiner H, Lubetzki C, Hartung HP, Montalban X, Uitdehaag BM, et al. 2016. Oral fingolimod in primary progressive multiple sclerosis (INFORMS): A phase 3, randomised, double-blind, placebo-controlled trial. Lancet 387: 1075-1084.

Miller AE, Wolinsky JS, Kappos L, Comi G, Freedman MS, Olsson TP, Bauer D, Benamor M, Truffinet P, O'Connor PW. 2014. Oral teriflunomide for patients with a first clinical episode suggestive of multiple sclerosis (TOPIC): A randomised, double-blind, placebo-controlled, phase 3 trial. Lancet Neurol 13: 977-986.

Mishra MK, Wang J, Silva C, Mack M, Yong VW. 2012. Kinetics of proinflammatory monocytes in a model of multiple sclerosis and its perturbation by laquinimod. Am J Pathol 181: 642-651.

Mitosek-Szewczyk K, Tabarkiewicz J, Wilczynska B, Lobejko K, Berbecki J, Nastaj M, Dworzanska E, Kolodziejczyk B, Stelmasiak Z, Rolinski J. 2013. Impact of cladribine therapy on changes in circulating dendritic cell subsets, T cells and B cells in patients with multiple sclerosis. J Neurol Sci 332: 35-40.

Muller S, Behnen M, Bieber K, Moller S, Hellberg L, Witte M, Hansel M, Zillikens D, Solbach W, Laskay T, et al. 2016. Dimethylfumarate impairs neutrophil functions. J Invest Dermatol 136: 117-126.
Munsell M, Frean M, Menzin J, Phillips AL. 2017. An evaluation of adherence in patients with multiple sclerosis newly initiating treatment with a self-injectable or an oral disease-modifying drug. Patient Prefer Adherence 11: 55-62.

Musella A, Mandolesi G, Gentile A, Rossi S, Studer V, Motta C, Sepman H, Fresegna D, Haji N, Paolillo A, et al. 2013. Cladribine interferes with IL- $1 \beta$ synaptic effects in experimental multiple sclerosis. J Neuroimmunol 264: 8-13.

Naismith RT, Claxton AE, Leigh-Pemberton RA, Du Y, Hard ML, von Moltke L, Wolinsky JS. 2016. Safety and tolerability of ALKS 8700 in relapsing-remitting multiple sclerosis: Phase 3 open-label study design (EVOLVE-MS1). ECTRIMS Online Library, Abstract P748.

Nieuwkamp DJ, Murk JL, van Oosten BW, Cremers CH, Killestein J, Viveen MC, Van Hecke W, Frijlink DW, Wattjes MP. 2015. PML in a patient without severe lymphocytopenia receiving dimethyl fumarate. $N$ Engl $\mathrm{J} \mathrm{Med}$ 372: 1474-1476

Noda H, Takeuchi H, Mizuno T, Suzumura A. 2013. Fingolimod phosphate promotes the neuroprotective effects of microglia. J Neuroimmunol 256: 13-18.

O’Connor P, Wolinsky JS, Confavreux C, Comi G, Kappos L, Olsson TP, Benzerdjeb H, Truffinet P, Wang L, Miller A, et al. 2011. Randomized trial of oral teriflunomide for relapsing multiple sclerosis. N Engl J Med 365: $1293-$ 1303.

O'Connor P, Comi G, Freedman MS, Miller AE, Kappos L, Bouchard JP, Lebrun-Frenay C, Mares J, Benamor M, Thangavelu K, et al. 2016. Long-term safety and efficacy of teriflunomide: Nine-year follow-up of the randomized TEMSO study. Neurology 86: 920-930.

Olsson T, Boster A, Fernandez O, Freedman MS, Pozzilli C, Bach D, Berkani O, Mueller MS, Sidorenko T, Radue EW et al. 2014. Oral ponesimod in relapsing-remitting multiple sclerosis: A randomised phase II trial. J Neurol Neurosurg Psychiatry 85: 1198-1208.

Pakpoor J, Disanto G, Altmann DR, Pavitt S, Turner BP, Marta M, Juliusson G, Baker D, Chataway J, Schmierer K. 2015. No evidence for higher risk of cancer in patients with multiple sclerosis taking cladribine. Neurol Neuroimmunol Neuroinflamm 2: e158.

Parodi B, Rossi S, Morando S, Cordano C, Bragoni A, Motta C, Usai C, Wipke BT, Scannevin RH, Mancardi GL, et al 2015. Fumarates modulate microglia activation through a novel HCAR2 signaling pathway and rescue synaptic dysregulation in inflamed CNS. Acta Neuropathol 130: 279295.

Peng H, Li H, Sheehy A, Cullen P, Allaire N, Scannevin RH. 2016. Dimethyl fumarate alters microglia phenotype and protects neurons against proinflammatory toxic microenvironments. J Neuroimmunol 299: 35-44.

Pitarokoili K, Ambrosius B, Schrewe L, Hayardeny L, Hayden M, Gold R. 2014. Laquinimod exerts strong clinical and immunomodulatory effects in Lewis rat experimental autoimmune neuritis. J Neuroimmunol 274: 38-45.

Pitarokoili K, Ambrosius B, Meyer D, Schrewe L, Gold R. 2015. Dimethyl fumarate ameliorates Lewis rat experimental autoimmune neuritis and mediates axonal protection. PloS ONE 10: e0143416.

Reick C, Ellrichmann G, Thone J, Scannevin RH, Saft C, Linker RA, Gold R. 2014. Neuroprotective dimethyl fu- 
marate synergizes with immunomodulatory interferon $\beta$ to provide enhanced axon protection in autoimmune neuroinflammation. Exp Neurol 257: 50-56.

Ringheim GE, Lee L, Laws-Ricker L, Delohery T, Liu L, Zhang D, Colletti N, Soos TJ, Schroeder K, Fanelli B, et al. 2013. Teriflunomide attenuates immunopathological changes in the Dark Agouti rat model of experimental autoimmune encephalomyelitis. Front Neurol 4: 169.

Ringshausen I, Oelsner M, Bogner C, Peschel C, Decker T. 2008. The immunomodulatory drug Leflunomide inhibits cell cycle progression of B-CLL cells. Leukemia 22: 635-638.

Rolland WB, Krafft PR, Lekic T, Klebe D, LeGrand J, Weldon AJ, Xu L, Zhang JH. 2017. Fingolimod confers neuroprotection through activation of Racl after experimental germinal matrix hemorrhage in rat pups. J Neurochem 140: 776-786.

Rosenkranz T, Novas M, Terborg C. 2015. PML in a patient with lymphocytopenia treated with dimethyl fumarate. $N$ Engl J Med 372: 1476-1478.

Runstrom A, Leanderson T, Ohlsson L, Axelsson B. 2006. Inhibition of the development of chronic experimental autoimmune encephalomyelitis by laquinimod (ABR$215062)$ in IFN- $\beta$ k.o. and wild type mice. J Neuroimmunol 173: 69-78.

Schimrigk S, Brune N, Hellwig K, Lukas C, Bellenberg B, Rieks M, Hoffmann V, Pohlau D, Przuntek H. 2006. Oral fumaric acid esters for the treatment of active multiple sclerosis: An open-label, baseline-controlled pilot study. Eur J Neurol 13: 604-610.

Schulze-Topphoff U, Varrin-Doyer M, Pekarek K, Spencer CM, Shetty A, Sagan SA, Cree BA, Sobel RA, Wipke BT, Steinman L, et al. 2016. Dimethyl fumarate treatment induces adaptive and innate immune modulation independent of Nrf2. Proc Natl Acad Sci 113: 4777-4782.

Selmaj K, Li DK, Hartung HP, Hemmer B, Kappos L, Freedman MS, Stuve O, Rieckmann P, Montalban X, Ziemssen T, et al. 2013. Siponimod for patients with relapsing-remitting multiple sclerosis (BOLD): An adaptive, doseranging, randomised, phase 2 study. Lancet Neurol 12: 756-767.

Singh V, Voss EV, Benardais K, Stangel M. 2012. Effects of 2chlorodeoxyadenosine (Cladribine) on primary rat microglia. J Neuroimmune Pharmacol 7: 939-950.

Slowik A, Schmidt T, Beyer C, Amor S, Clarner T, Kipp M. 2015. The sphingosine 1-phosphate receptor agonist FTY720 is neuroprotective after cuprizone-induced CNS demyelination. Br J Pharmacol 172: 80-92.

Stoppe M, Thoma E, Liebert UG, Major EO, Hoffmann KT, Classen J, Then Bergh F. 2014. Cerebellar manifestation of PML under fumarate and after efalizumab treatment of psoriasis. J Neurol 261: 1021-1024.

Strassburger-Krogias K, Ellrichmann G, Krogias C, Altmeyer P, Chan A, Gold R. 2014. Fumarate treatment in progressive forms of multiple sclerosis: First results of a single-center observational study. Ther Adv Neurol Disord 7: 232-238.

Teschner S, Gerke P, Geyer M, Wilpert J, Krumme B, Benzing T, Walz G. 2009. Leflunomide therapy for polyomavirus-induced allograft nephropathy: Efficient BK virus elimination without increased risk of rejection. Transplant Proc 41: 2533-2538.

Thone J, Ellrichmann G, Seubert S, Peruga I, Lee DH, Conrad R, Hayardeny L, Comi G, Wiese S, Linker RA, et al. 2012. Modulation of autoimmune demyelination by laquinimod via induction of brain-derived neurotrophic factor. Am J Pathol 180: 267-274.

Toubi E, Nussbaum S, Staun-Ram E, Snir A, Melamed D, Hayardeny L, Miller A. 2012. Laquinimod modulates B cells and their regulatory effects on T cells in multiple sclerosis. J Neuroimmunol 251: 45-54.

van Oosten BW, Killestein J, Barkhof F, Polman CH, Wattjes MP. 2013. PML in a patient treated with dimethyl fumarate from a compounding pharmacy. N Engl J Med 368: 1658-1659.

Varrin-Doyer M, Pekarek KL, Spencer CM, Bernard CC, Sobel RA, Cree BA, Schulze-Topphoff U, Zamvil SS. 2016. Treatment of spontaneous EAE by laquinimod reduces Tfh, B cell aggregates, and disease progression. Neurol Neuroimmunol Neuroinflamm 3: e272.

Vollmer TL, Sorensen PS, Selmaj K, Zipp F, Havrdova E, Cohen JA, Sasson N, Gilgun-Sherki Y, Arnold DL 2014. A randomized placebo-controlled phase III trial of oral laquinimod for multiple sclerosis. J Neurol 261: 773-783.

Wegner C, Stadelmann C, Pfortner R, Raymond E, Feigelson S, Alon R, Timan B, Hayardeny L, Brück W. 2010. Laquinimod interferes with migratory capacity of $\mathrm{T}$ cells and reduces IL-17 levels, inflammatory demyelination and acute axonal damage in mice with experimental autoimmune encephalomyelitis. J Neuroimmunol 227: 133-143.

Wei Y, Yemisci M, Kim HH, Yung LM, Shin HK, Hwang SK, Guo S, Qin T, Alsharif N, Brinkmann V, et al. 2011. Fingolimod provides long-term protection in rodent models of cerebral ischemia. Ann Neurol 69: 119-129.

Wostradowski T, Prajeeth CK, Gudi V, Kronenberg J, Witte S, Brieskorn M, Stangel M. 2016. In vitro evaluation of physiologically relevant concentrations of teriflunomide on activation and proliferation of primary rodent microglia. J Neuroinflamm 13: 250.

Wu H, Wang X, Gao J, Liang S, Hao Y, Sun C, Xia W, Cao Y, Wu L. 2017. Fingolimod (FTY720) attenuates social deficits, learning and memory impairments, neuronal loss and neuroinflammation in the rat model of autism. Life Sci 173: 43-54

Zhao P, Yang X, Yang L, Li M, Wood K, Liu Q, Zhu X. 2017. Neuroprotective effects of fingolimod in mouse models of Parkinson's disease. FASEB J 31: 172-179. 